\title{
Evaluation of Vehicular Discomfort Measures Produced by Speed Bumps Using Numerical Simulation
}

\author{
Lima E. A. , Silveira M. E., José Avila Júnior, Carlos Aureio Silva Carvalho, \\ Maria Fernanda Lousada Antunes, Diego Morais Junqueira
}

Department of Mechanical Engineering, Federal University of São João Del Rei (UFSJ), São João Del Rei, Brazil

\begin{abstract}
In the design of automotive components the use of numerical simulations has contributed to reducing the design time, decreasing the prototypes costs and increasing reliability of the final product. However is necessary a investigation on human body vertical vibrations transmitted by different types of vehicle for the purpose of recognition the danger and guiding to eliminate of risks of discomfort theirs. This study, the object is to compare the discomfort levels of occupants when different vehicles (car, bike and bus) move over a speed bump. The results show that wheelbase, wheel size and vehicle weight can lead to different vehicular discomfort results. Results of the study demonstrated that heavy vehicles occupants (bus or truck) are subject to discomfort greater than occupants of light vehicles (cars and motorcycles) ones.
\end{abstract}

Keywords Numerical Simulation, Speed Bumps, Mechanical Vibrations, Automotive Discomfort

\section{Introduction}

Vehicles are subject to forces imposed by ground irregularities during their movement. These forces can act on various car systems generating noise, vibration and fatigue [1]. Speed bump, a kind of ground elevation made to reduce vehicle speed, is highly used as a traffic control, granting more mobility to pedestrians and preventing accidents. Speed bumps can vary in shape and dimensions; therefore, they can generate different responses from drivers and components of different vehicle types. Other factors can also influence the vehicle response, like its weight, tire diameter and wheelbase.

The comfort level of a vehicle is highly related to its tires and the amplitude of vertical acceleration, latter the main responsible for absorbing part of shocks in the vertical direction. However, the acceleration is more appropriate to measure a vehicle comfort level [2, 3]. The root mean square (RMS), as shown in Eq. (1), generally is the method used to quantify the vibration severity levels that a man is exposed to in the absence of impacts $[4,5]$.

$$
\operatorname{RMS}=\left(\frac{1}{N} \sum_{i=1}^{N} a_{i}^{2}\right)^{1 / 2}
$$

$a_{i}$ is the weighted acceleration $\left(\mathrm{m} . \mathrm{s}^{-2}\right)$ and $N$ are the number of data points.

* Corresponding author:

eduardoa.lima@hotmail.com (Lima E. A.)

Published online at http://journal.sapub.org/jmea

Copyright (C) 2015 Scientific \& Academic Publishing. All Rights Reserved
Shock-type vibrations are frequently experienced in vehicles excited by impulsive input, such as bumps in the road, and cause discomfort [6]. The reference discomfort levels for a driver and passengers are shown in Table 1.

Table 1. Vehicle discomfort measurements [6]

\begin{tabular}{ll}
\hline RMS Acceleration $\left(\mathbf{m . s}^{-2}\right)$ & Comfort Level \\
\hline lower than 0.315 & comfortable \\
between 0.315 and 0.63 & a bit uncomfortable \\
between 0.5 and 1 & middling uncomfortable \\
between 0.8 and 1.6 & uncomfortable \\
between 1.25 and 2.5 & highly uncomfortable \\
higher than 2 & extremely uncomfortable \\
\hline
\end{tabular}

For transient vertical movements with either a single shock or a combination of shock and vibration [6, 7], it's also necessary to calculate the crest factor, as shown in Eq. (2), that indicates the total damage a vehicle occupant suffers due to the vibration response.

$$
\text { Crest_factor }=\frac{\text { Abs }\left(\text { Pico }_{\max }\right)}{\text { RMS }}
$$

Abs $\left(\mathrm{Pico}_{\max }\right)$ is the maximum acceleration peak value $\left(\mathrm{m} . \mathrm{s}^{-2}\right)$.

Since the vibration can vary during the vehicle movement, the time interval used to calculate RMS values becomes inadequate to measure it, being the cumulative measurement method, also called dose method, more secure and consistent. The measured parameter used in this case is the VDV (Vibration dose Value), as shown in Eq. (3). It can be applied to both shock and analysis of daily vibration exposure of different types [8]. As expressed in $m . s^{-1.75}$, it has been 
proved that there is a good correlation between the method of analysis and human sensitivity to vibration demonstrated by experimental studies of exposure to all types of vibration, $[9,10]$.

$$
\operatorname{VDV}=\left(\frac{1}{f_{s}} \sum_{i=1}^{N} a_{i}^{4}\right)^{1 / 4}
$$

$A_{\mathrm{i}}(t)$ is registration of the weighted acceleration, in $\mathrm{m} . \mathrm{s}^{-2}$; $N$ is the number of points of the recording time;

$f_{s}$ is the frequency of acquisition in $\mathrm{Hz}$;

According to [11] the magnitudes of vibration producing VDV's in the range of $8.5 \mathrm{~m} . \mathrm{s}^{-1,75}$ trigger discomfort medium and VDV's in the range of $15 \mathrm{~m} \cdot \mathrm{s}^{-1,75}$ usually trigger severe discomfort. However there is no consensus among the scientific community regarding the influence of the magnitude of the VDV, as [6]. Other parameters utilized to measure the discomfort are the maximum and minimum values of acceleration peaks, Eq. (4) and (5), and distance between both, Eq. (6).

$$
\begin{aligned}
\text { Peak }(+) & =\mathrm{a}_{\max }(\mathrm{t}) \mathrm{em} \Delta \mathrm{t} \\
\text { Peak }(-) & =\mathrm{a}_{\min }(\mathrm{t}) \mathrm{em} \Delta \mathrm{t} \\
\text { Peak_to_Peak } & =[\operatorname{Pico}(+)|+| \operatorname{Pico}(-)]
\end{aligned}
$$

As seen in the literature, there is no consensus on the ideal magnitude to evaluate the level of discomfort of the passenger (or driver) due to vertical ripples. Moreover the vehicle vibration mode is related to the pavement irregularity, causing major or lesser discomfort in the passenger [16]. Therefore, for this work, were evaluated all the parameters described in Eq. (1) to (6).

\section{Methodology}

In order to compare the discomfort between different types of vehicles (car, motorcycle and bus), a model was created in CAD software (Computer Aided Design), Figure 3a, 3b and 3c.

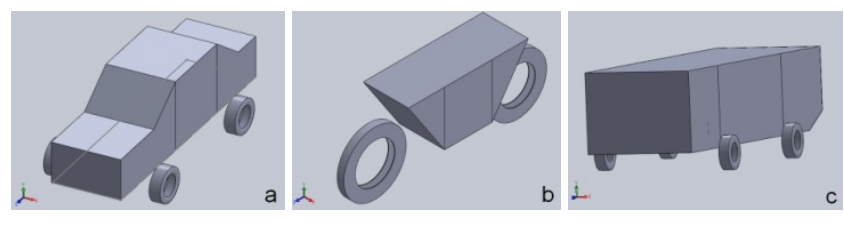

Figure 3. CAD models

The models have been simplified to facilitate the simulation and reduce the computational cost. In each type of vehicle was varied the wheelbase and wheel diameter. The minimum and maximum values are shown in the appendix (Table 2).

The CAD models were exported to HyperMesh software for finite element discretization. The structures were modeled by shell elements, the suspension arms by beam elements and the total concentrated mass of the vehicle by a $1 \mathrm{D}$ element. The tires were modeled with only the properties of rubber (assuming isotropic linear behavior) and air through a monitored volume, where the pressure and volume are controlled by means of an adiabatic relationship.

As boundary conditions, an initial speed and a vertical acceleration was imposed (gravity) on the entire model and contact conditions were put between the tires and the ground / speed bump. Due to the contact conditions and time dependent, non-linear dynamic analysis was performed.

All simulations kept some common conditions such as the distance from the speed bump, velocity of $30 \mathrm{~km} / \mathrm{h}$ towards the speed bump and simulation time. In addition, the mass of models has remained constant, with the car being $1000 \mathrm{~kg}$, the motorcycle $170 \mathrm{~kg}$ and the bus $6000 \mathrm{~kg}$.

The dummies were modeled as a rigid solid body (3D) and the seat with 1D elements of type spring / dampers (Figure 4). The mass, stiffness and damping were based on [10].

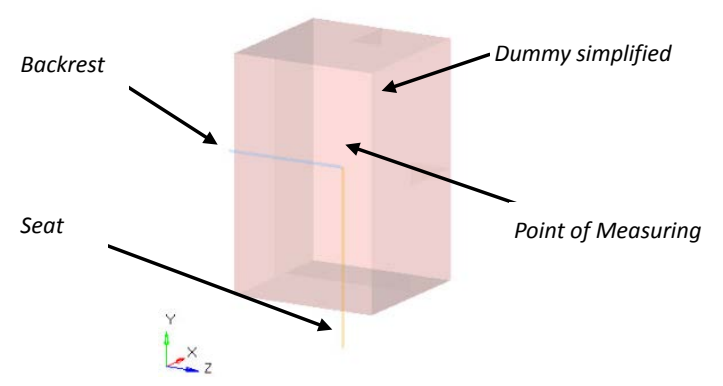

Figure 4. Dummy model

In the car model, Figure 5, the suspensions are double wishbone type. The spring stiffness values and damping coefficient are: $\mathrm{K}=23 \mathrm{~N} \cdot \mathrm{mm}^{-1}$ and $\mathrm{C}=1,2 \mathrm{~N} . \mathrm{s} \cdot \mathrm{mm}^{-1}$, [12].

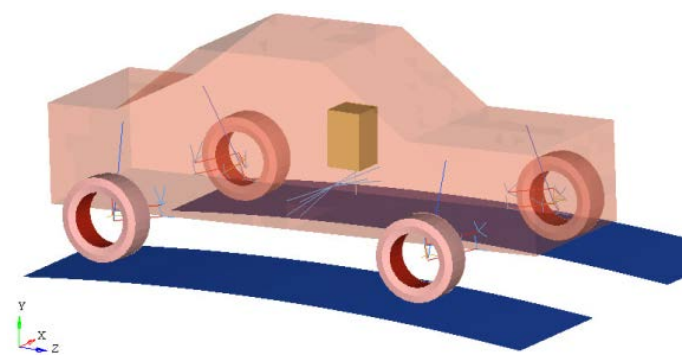

Figure 5. Model of Car (Car_1_ST)

The motorcycle suspensions are upside down - type. This type is the same configuration for rear wheel and the front wheel, as shown in Figure 6. The values spring / damper were calculated linearly to the mass of the motorcycle, [12].

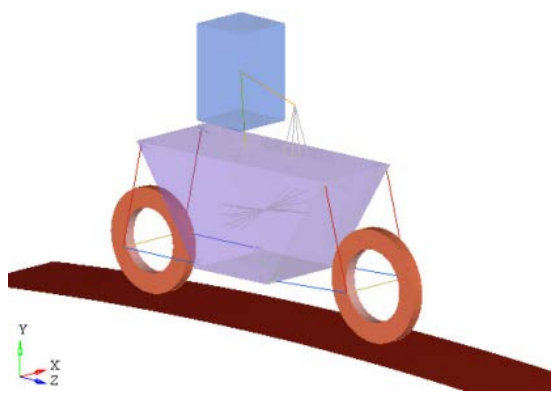

Figure 6. Model of motorcycle (Moto_1_ST) 
The bus suspensions are rigid axle - type [13]. The values spring / damper were calculated linearly to the mass of the bus, [12]. In addition, the discomfort was evaluated in two different points: P1 (representing the driver) and P2 (representing the passenger in the middle of the vehicle), as shown in Figure 7.

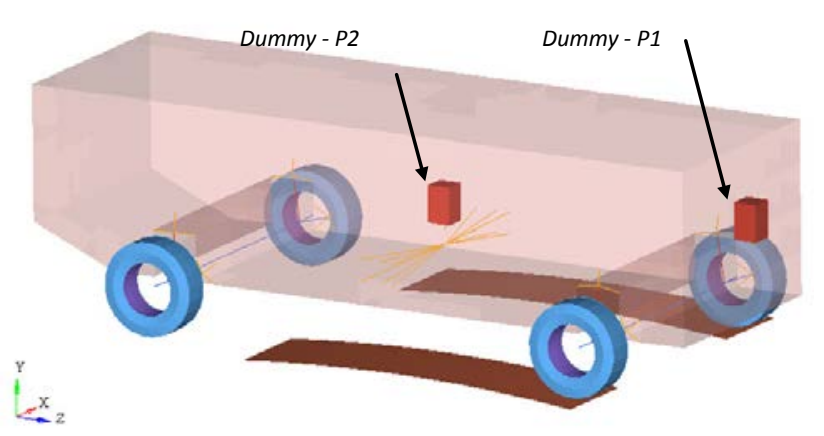

Figure 7. Model of bus (Bus_1_St)

The Radioss (Solver) software, used on the numerical simulations, is based on nonlinear geometry solutions Newmark integration scheme, Eq. (7). The equilibrium equation of a dynamic analysis discretised in finite elements can be given as follows:

$$
\mathrm{M} \ddot{\mathrm{U}}+C \dot{U}+k U=P
$$

$M$ is the mass matrix, $C$ is the damping matrix and $K$ is the stiffness matrix. These matrices are derived using finite elements method. The vector $P$ describes the external loads and $u$ is the displacement vector, as [14].

All solutions can be derived from it and are formulated in terms of a time history, Figure 8.

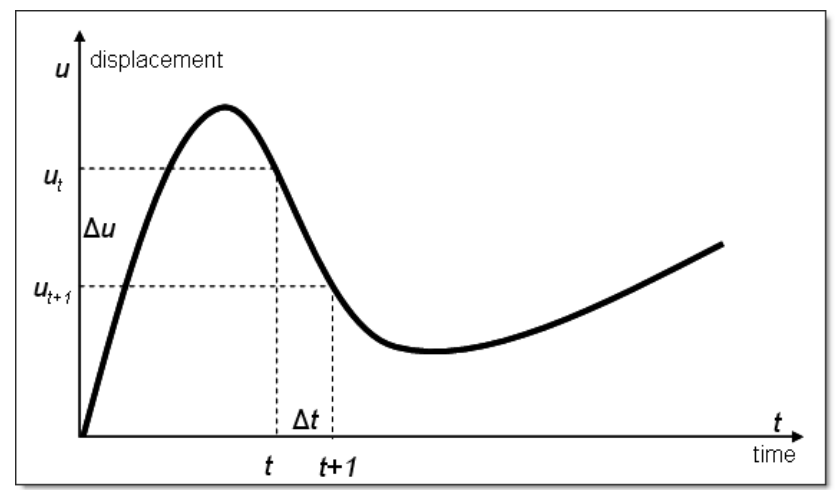

Figure 8. Time history [15]

The state vector is computed as:

$$
\begin{gathered}
\dot{U}_{t+1}=\dot{U}_{t}+\Delta t\left[(1-\gamma) \ddot{U}_{t}+\gamma \ddot{U}_{t+1}\right] \\
\left.U_{t+1}=U_{t}+\Delta t \dot{U}_{t}+(1 / 2-\beta) \Delta t^{2} \ddot{U}_{t}+\beta \Delta t^{2} \ddot{U}_{t+1}\right]
\end{gathered}
$$

Replacing in the equation (7):

$$
\begin{aligned}
& {\left[M+\gamma \Delta t C+\beta \Delta t^{2} K\right] \ddot{U}_{t}+1=} \\
& P-C\left[\dot{U}_{t}+(1-\gamma) \Delta t\right] \ddot{U}_{t}-K\left[U_{t}+\Delta t \dot{U}_{t}+(1 / 2-\beta) \Delta t^{2} \ddot{U}_{t}\right]
\end{aligned}
$$

This can be written as:

$$
\begin{gathered}
U_{t+1}=U_{t}+\Delta t U_{t} \\
{\left[\frac{1}{\beta \Delta t^{2}} M+\frac{\gamma}{\beta \Delta t} C+K\right] \Delta U_{t}=\Delta P_{t} \Rightarrow A \Delta U=P}
\end{gathered}
$$

$A$ is the dynamic stiffness.

Newton method is utilized for nonlinear time - dependent problems, because it requires an additional iteration loop at each time step. An explicit integration scheme can be derived from the Newmark by setting:

$$
\begin{gathered}
\gamma=1 / 2, \beta=0 \\
\dot{U}_{t+1}=\dot{U}_{t}+1 / 2 \Delta t\left[\ddot{U}_{t}+\ddot{U}_{t+1}\right] \\
U_{t+1}=\dot{U}_{t}+\Delta t \dot{U}_{t}+1 / 2 \Delta t^{2} \ddot{U}_{t}
\end{gathered}
$$

These relationships in the explicit integration scheme can be derived:

$$
\begin{gathered}
\dot{U}_{t+1 / 2}=\dot{U}_{t-1 / 2}+\Delta t_{12} \ddot{U}_{t} \\
\dot{U}_{t+1}=U_{t}+\Delta t_{2} \dot{U}_{t+1 / 2} \\
\ddot{U}_{t+1}=P-C \dot{U}_{t+1 / 2}-K U_{t+1}
\end{gathered}
$$

This relationship can be seen in Figure 9.

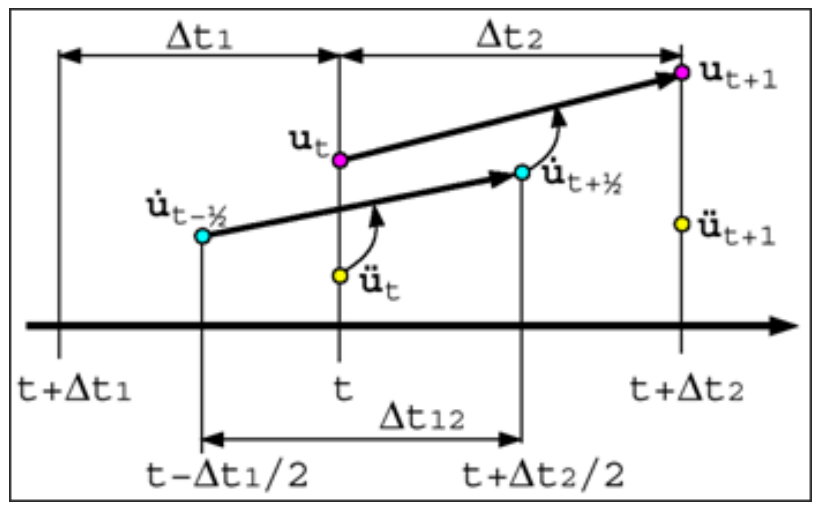

Figure 9. Explicit integration [15]

Assuming that Eq. (20), the equation of motion for the central differences scheme simplifies:

$$
C \dot{U}_{t+1} \approx C \dot{U}_{t+1 / 2}
$$




$$
\begin{aligned}
& M \ddot{U}_{t+1}=P-C \dot{U}_{t+1}-K U_{t+1} \\
& \quad \ddot{U}_{t+1}=P-\int B_{t+1}^{t} \sigma_{t+1} d V
\end{aligned}
$$

The time step must always be smaller than the critical time step to ensure stability of the solution. The critical time step depends on the highest frequency in the system and is computed from the corresponding angular frequency $\omega_{\max }$, Eq. (22), [14]:

$$
\Delta t_{c r}=\frac{2}{\omega_{\text {max }}}
$$

For a discrete system, the time step must be small enough to stimulate all frequencies in the finite element mesh, Eq. (23).

$$
\Delta t \leq \frac{I_{C}}{C}
$$

$I_{c}$ represents the critical length of an element and $C$, the speed of sound in the given material.

Different ways of time step control are available. The default method is the nodal time step which is computed from the nodal mass $m$ and the equivalent nodal stiffness $\mathrm{k}$, Eq (24).

$$
\Delta t_{C m}=\min \sqrt[n]{2 m / K}
$$

From the results, it was possible to plot graphs of the accelerations that act vertically in the center of each occupant at the designated time, Figure 10.

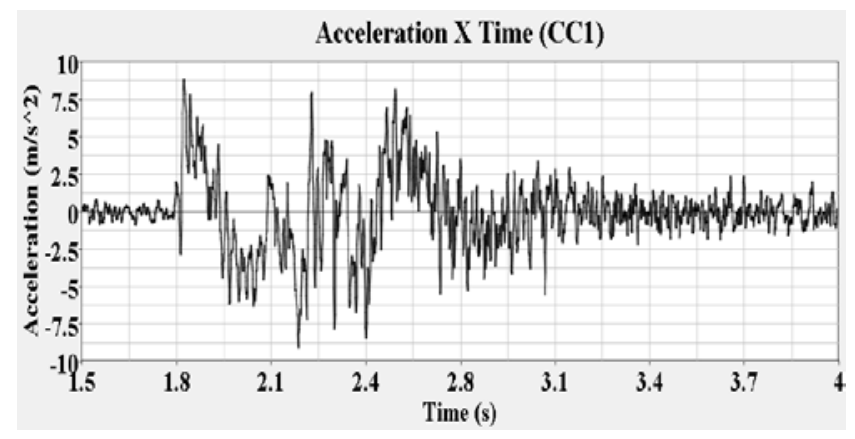

Figure 10. Example of Acceleration Graphics in Car_1_ST condition

\section{Results}

However, it can be difficult to measure and evaluate the discomfort produced only by the acceleration graph as in Figure 10. Thus discomfort analyses were done using the quantities described in Eq. (1), (2) (3), (4), (5) and (6), the results of which will be discussed in the following graphs.

Figure 11 shows the results of the variations of wheelbase (WB) for the car. It can be seen that for the Peaks, VDV and RMS, the longer the WB, the higher the discomfort. Probably, this is due to pitching rotation of the vehicle. However the Crest Factor indicates that a minor WB can be worse.

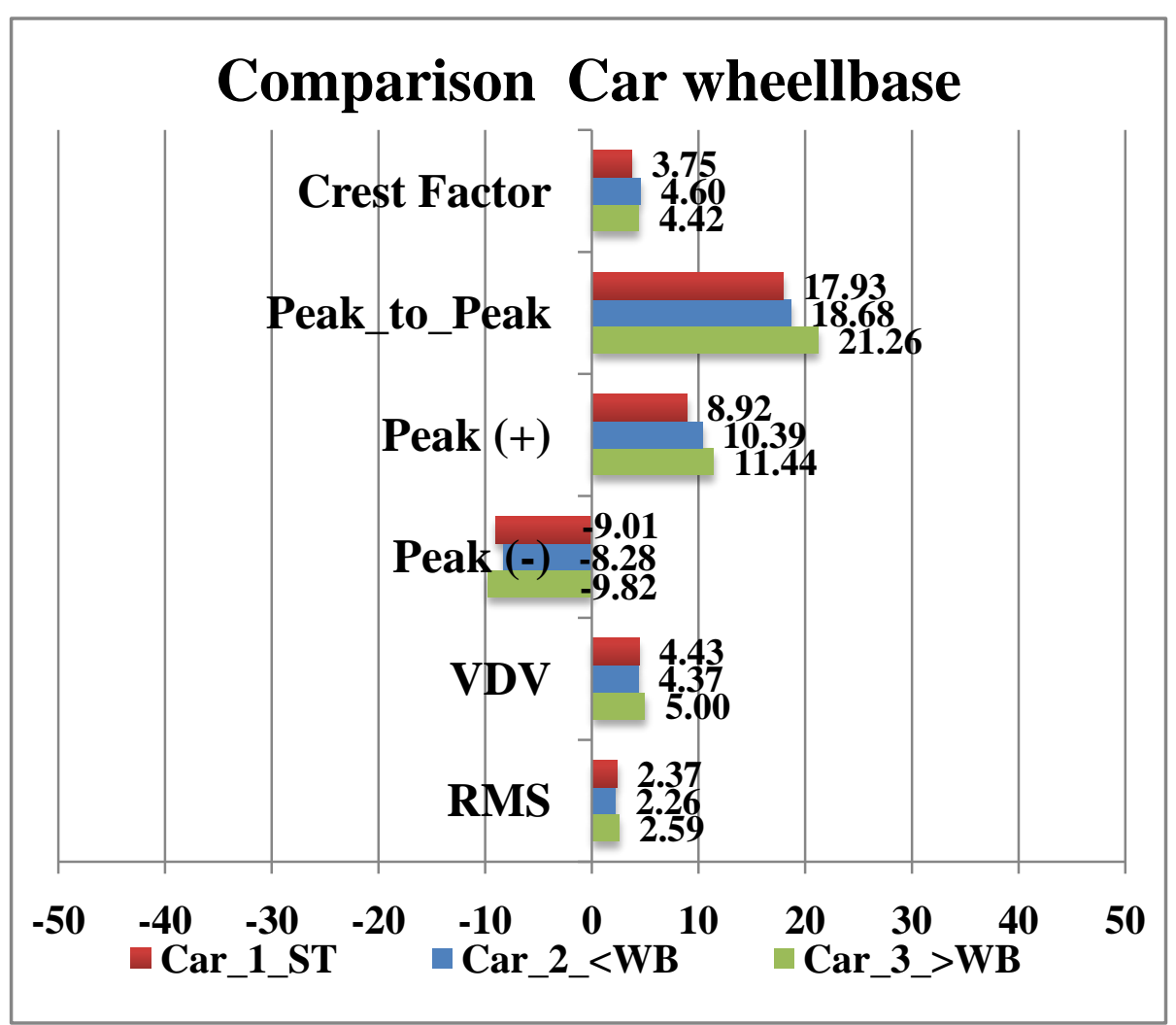

Figure 11. Comparison between differents of wheelbase of car 


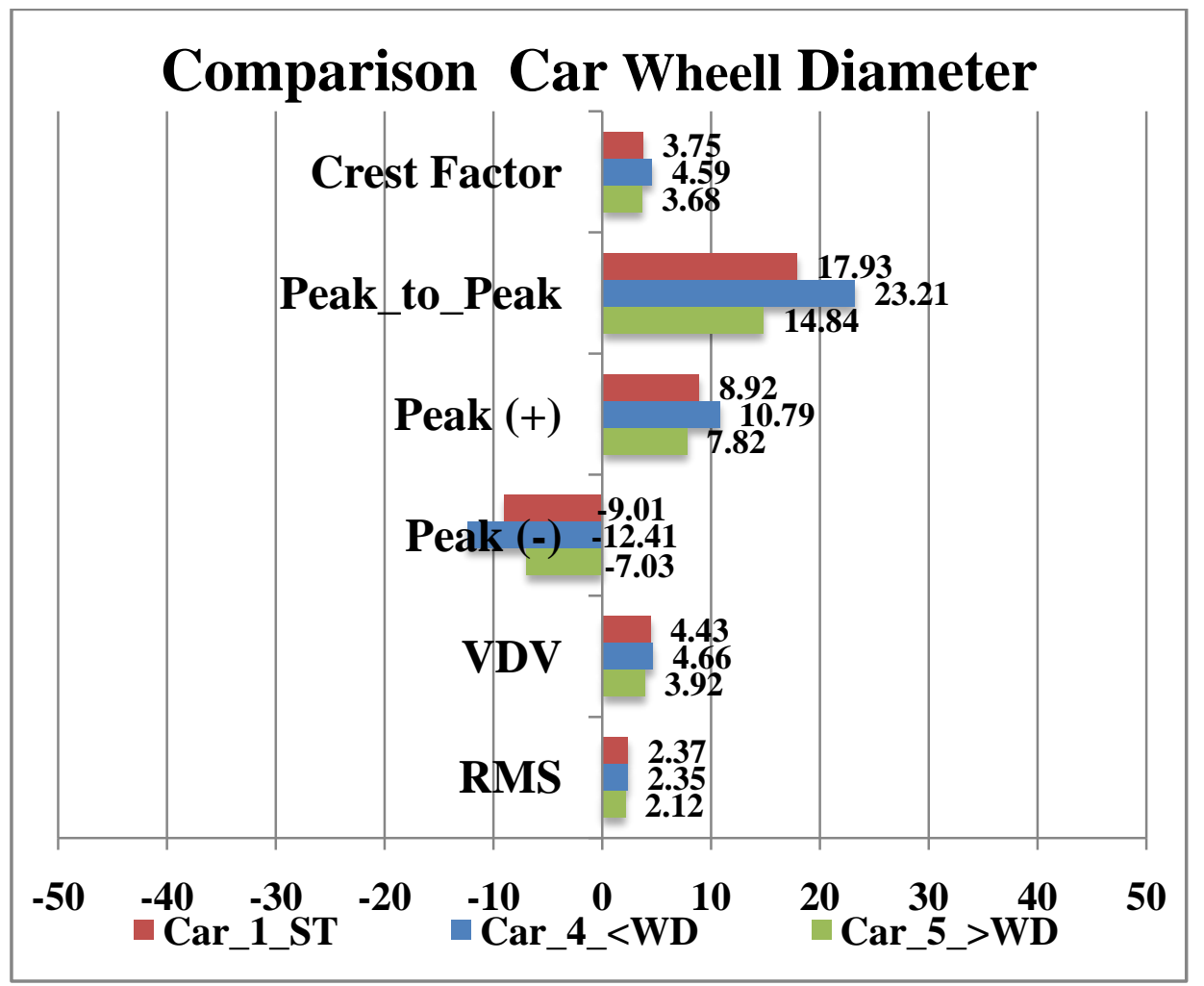

Figure 12. Comparison between differents of wheel diameter of car

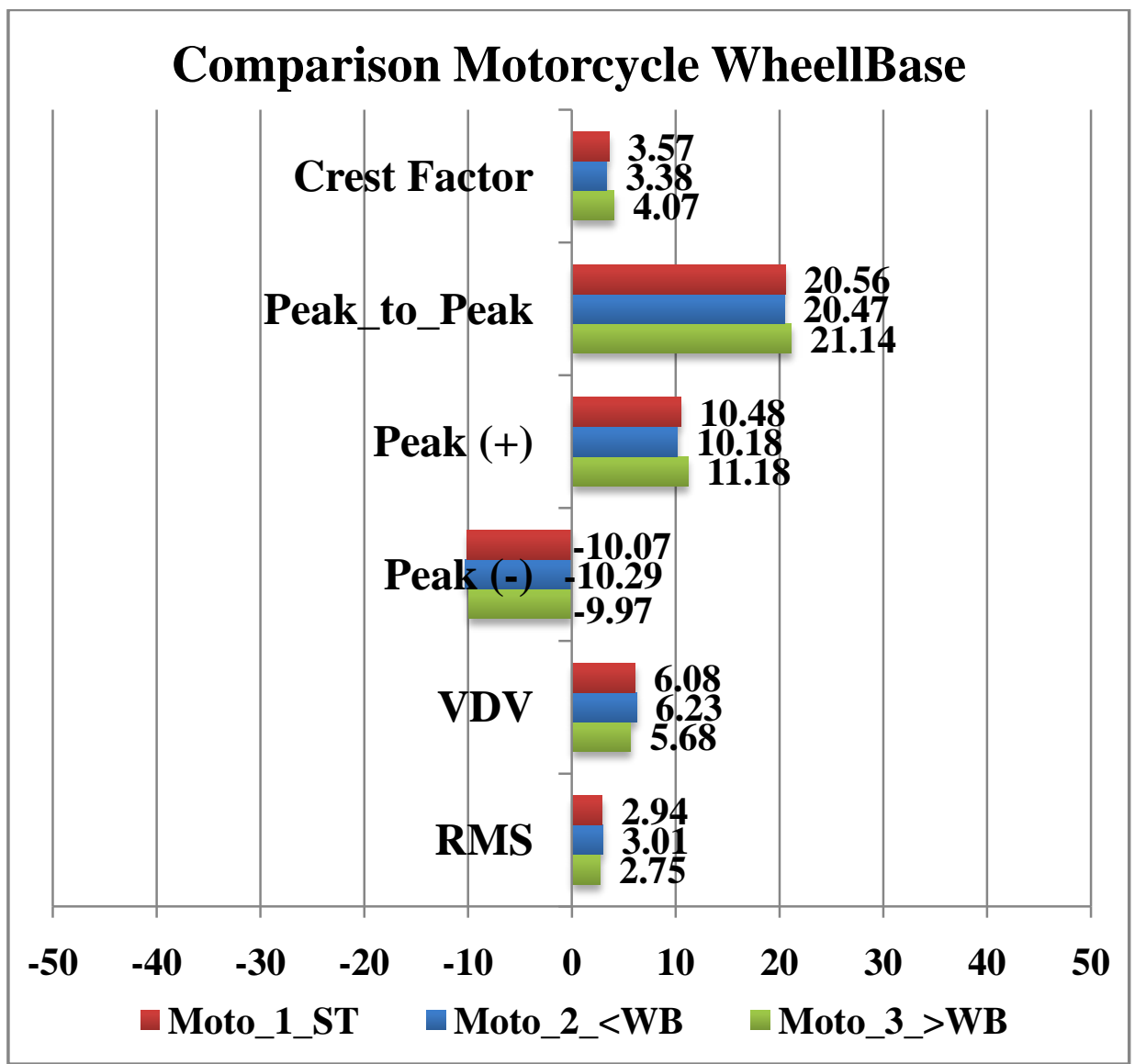

Figure 13. Comparison between differents wheelbase of motorcycle 


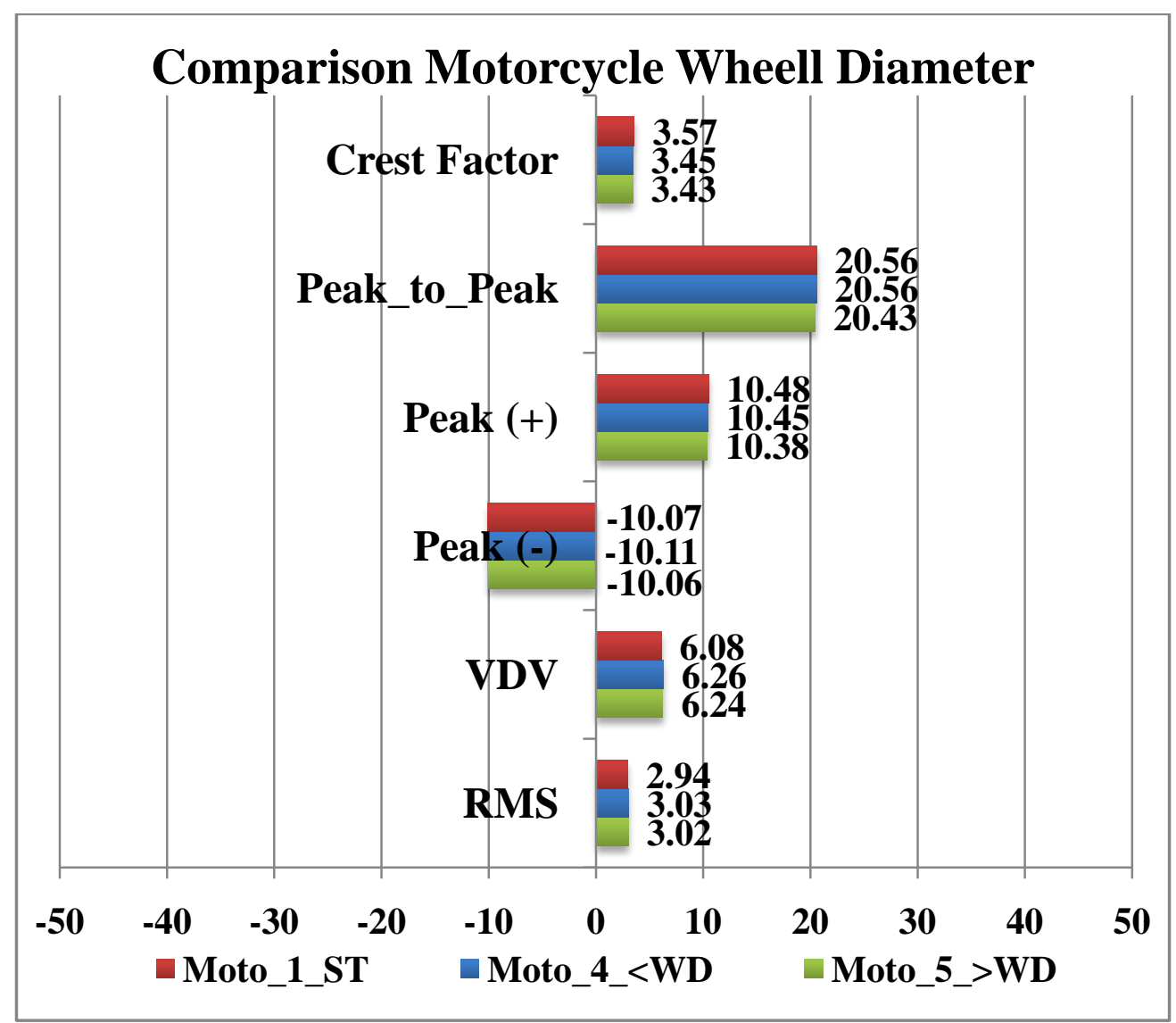

Figure 14. Comparison between differents wheel diameter of motorcycle

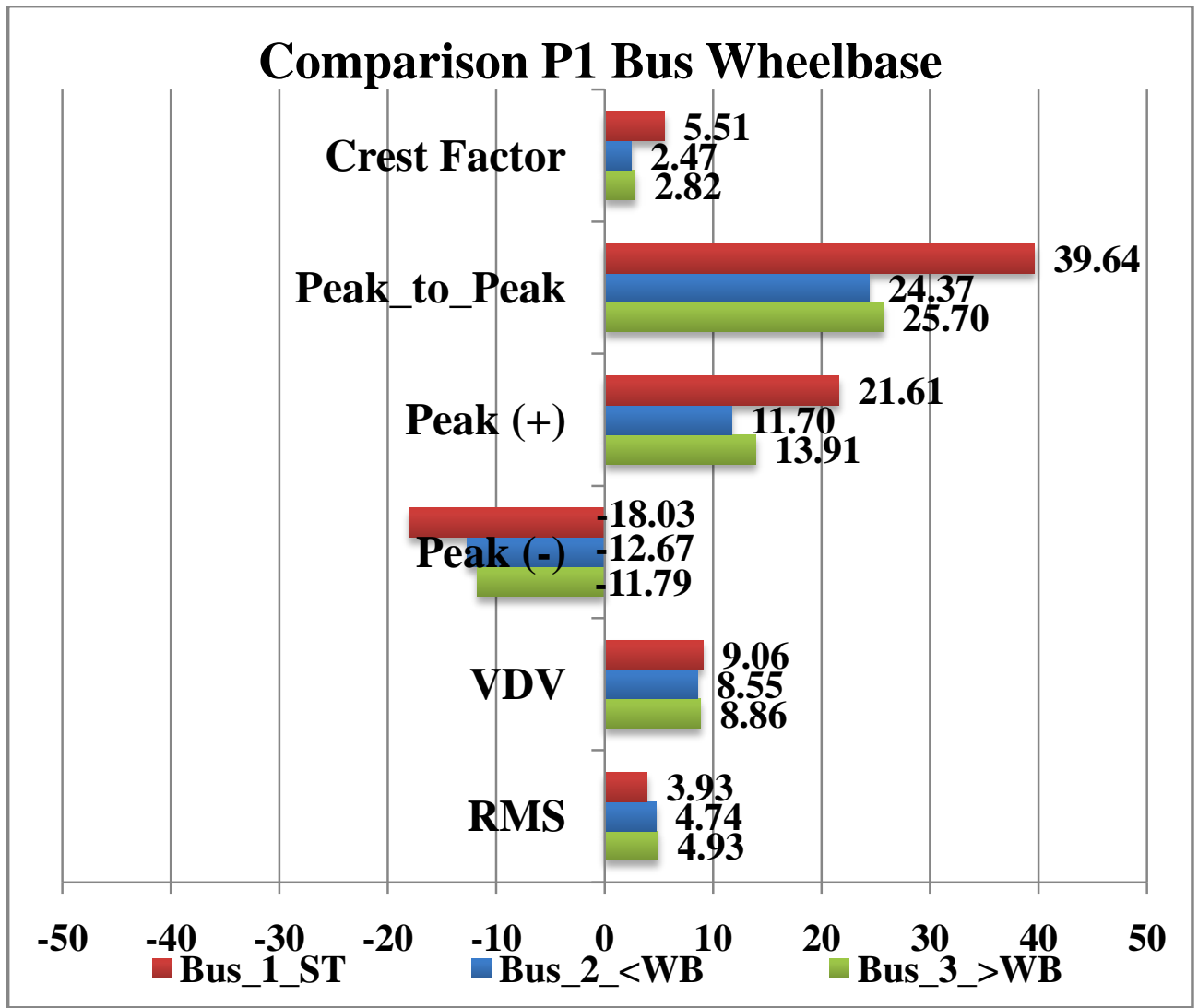

Figure 15. Comparison between differents wheelbase of P1 bus 


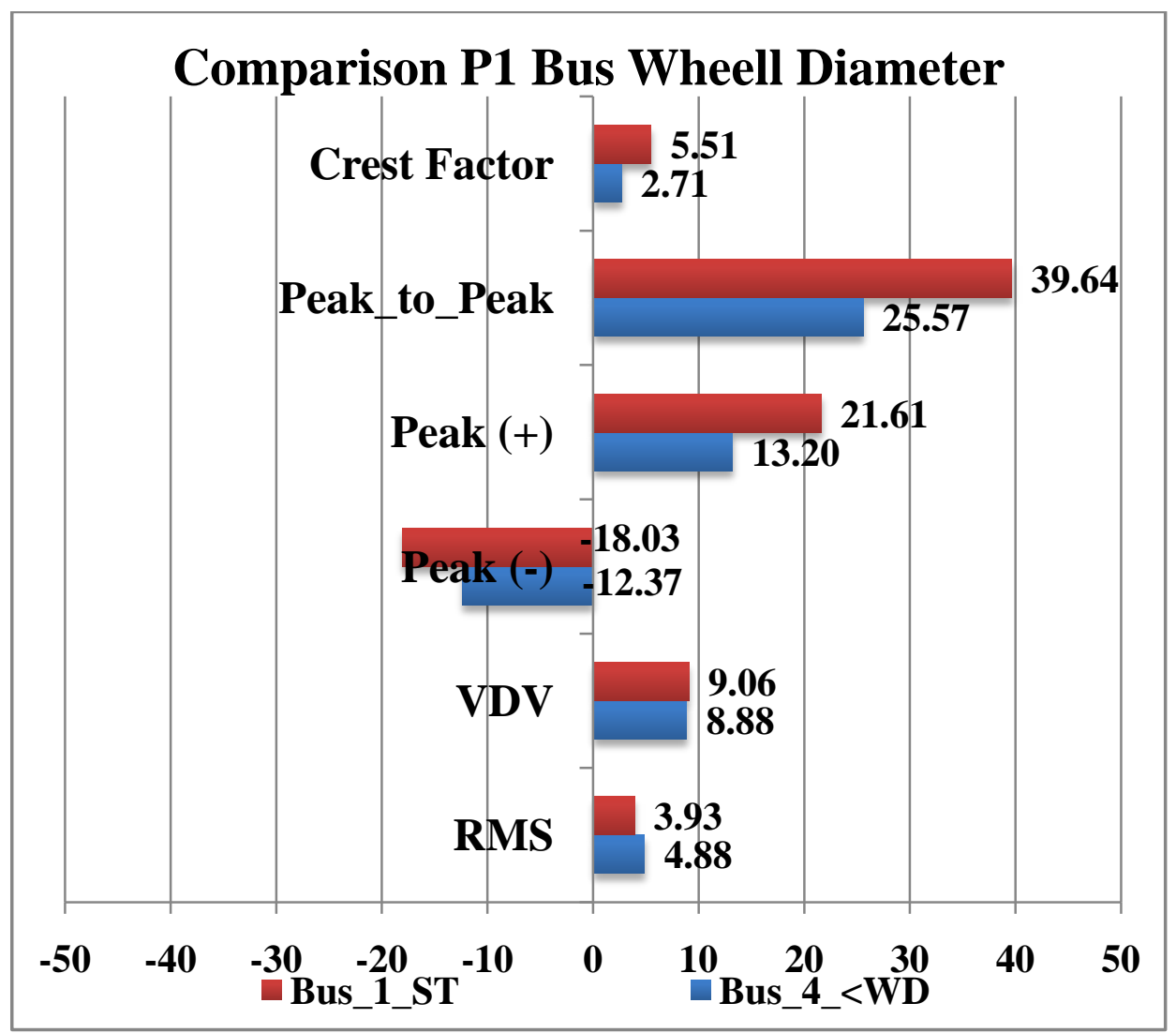

Figure 16. Comparison between differents wheel diameter of P1 bus

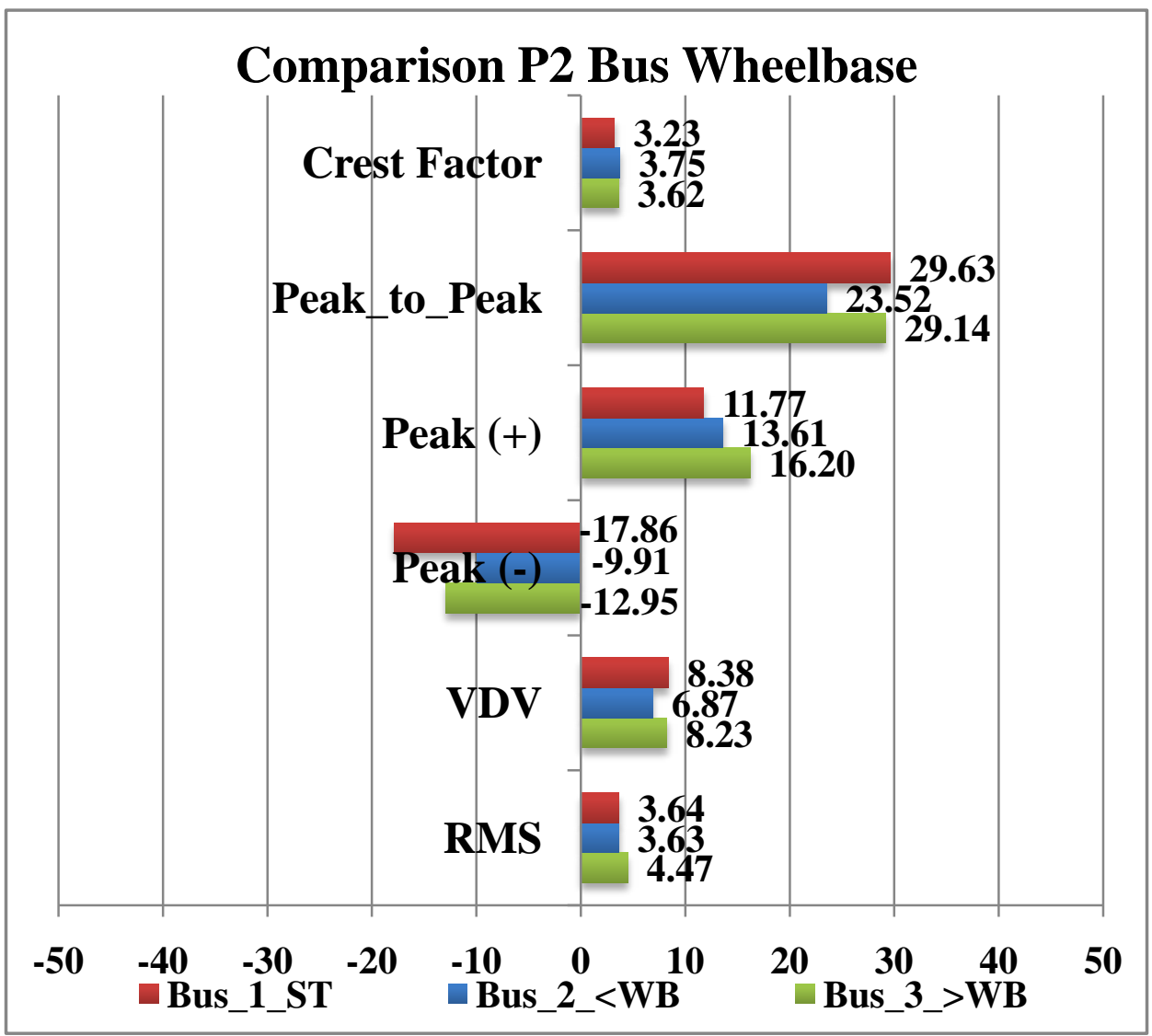

Figure 17. Comparison between differents wheelbase of P2 bus 
Figure 12 shows the results of the variations of wheel diameter (WD) for the same car. The results demonstrated that for all the quantities, the vehicle with minor WD has a considerable discomfort. This happened due to the geometric center of the tire is close to the ground. Although the RMS has been higher in standard, the VDV was higher in the minor WD.

In Figure 13 show the WB results for the motorcycle. Unlike what happened in the car, the variation of the WB didn't have significant changes over the discomfort. In some cases (Crest Factor and Peaks) the larger WB has a discrete influence, while in others (VDV and RMS) the WB was the smallest.

Figure 14 it can be seen the results of WD for the motorcycle. In relation to standard model (ST), the variation of the WD was insignificant, compared to the car. In practice it is known that the smallest WD is more uncomfortable. Perhaps the suspension model adopted is not the most suitable for this type of analysis.

Figure 15 shows the results for the WB of the driver (P1) of the bus. For the proposed model, it can be noted that the original WB was the worst case for all the measures, except for the RMS. The largest WB was slightly more uncomfortable than the smallest WB analyzed.

Figure 16 shows the influence of WD on the passenger P1.
From the results, unlike the car, the smallest WD generated less discomfort than original WD. It was observed in all the measures (except the RMS).

The results for the passenger P2 are shown in Figure 17. It can be noted that the P2 had less discomfort than P1 in all measures. The fact that $\mathrm{P} 2$ is in middle of the bus can have decreased the discomfort due to moment of bus over the passenger.

In relation to Wheel Diameter (WD), the same behavior was observed. However, the Crest Factor and Peak to Peak have increased their measures for standard bus.

After the evaluation of each type of vehicle separately, all standard vehicles were analyzed together (car, motorcycle and bus). The Figures 19, 20 and 21 show the RMS, VDV and Peak to Peak measures for these vehicles (the bus was analyzed in two point: P1 and P2). It can be observed that for all measures the behavior was similar, where the bus had major discomfort followed by the motorcycle and the car respectively. The results showed that the mass, geometry and position of the driver are very important on the evaluation of discomfort. The correct design of a speed bumper depends mainly of on the type of vehicle in route, because a speed bumper may be effective to penalize a type of vehicle (like bus), but may be tolerant with others (like a small car).

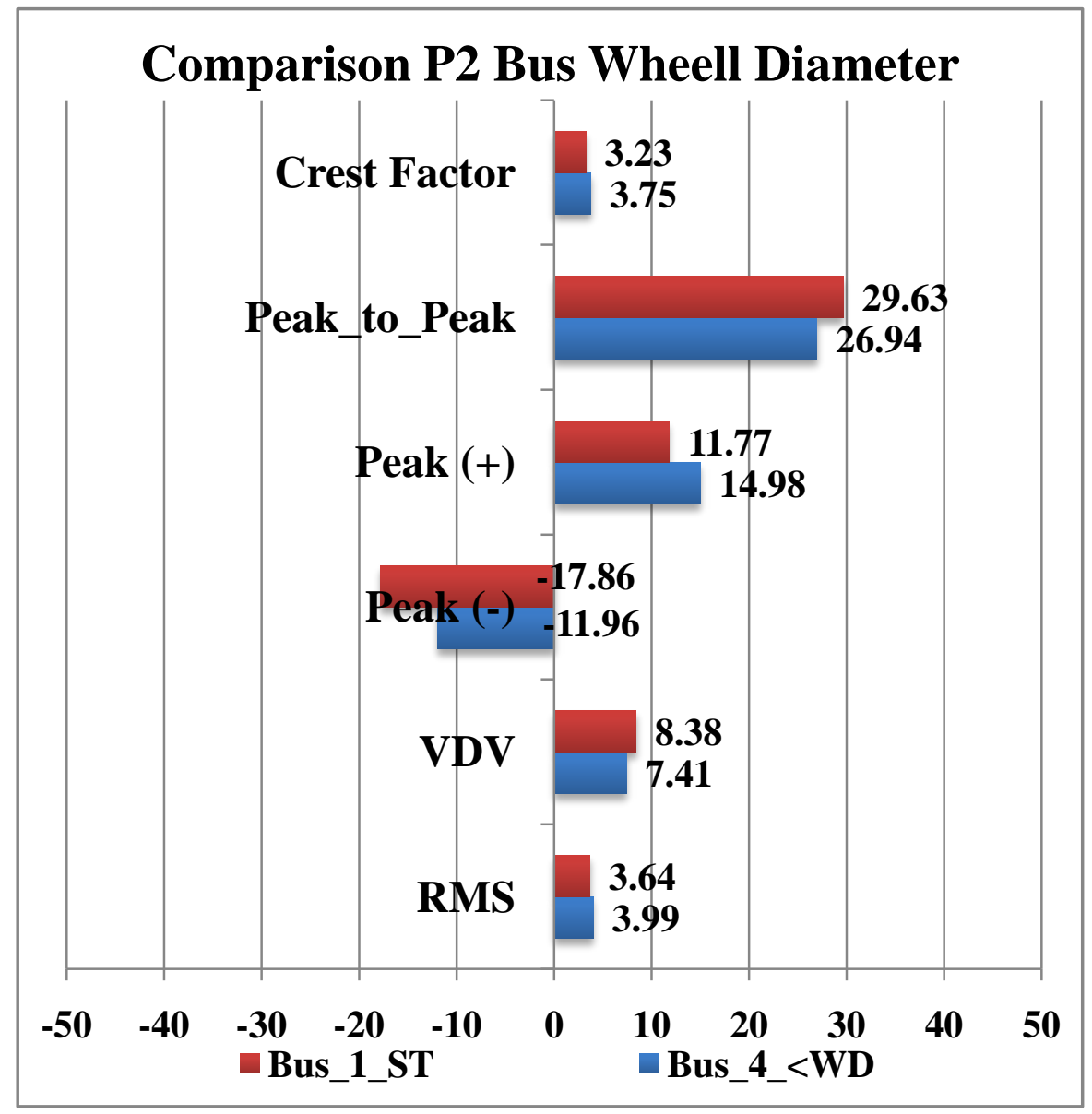

Figure 18. Comparison between differents wheel Diameter of P2 bus 


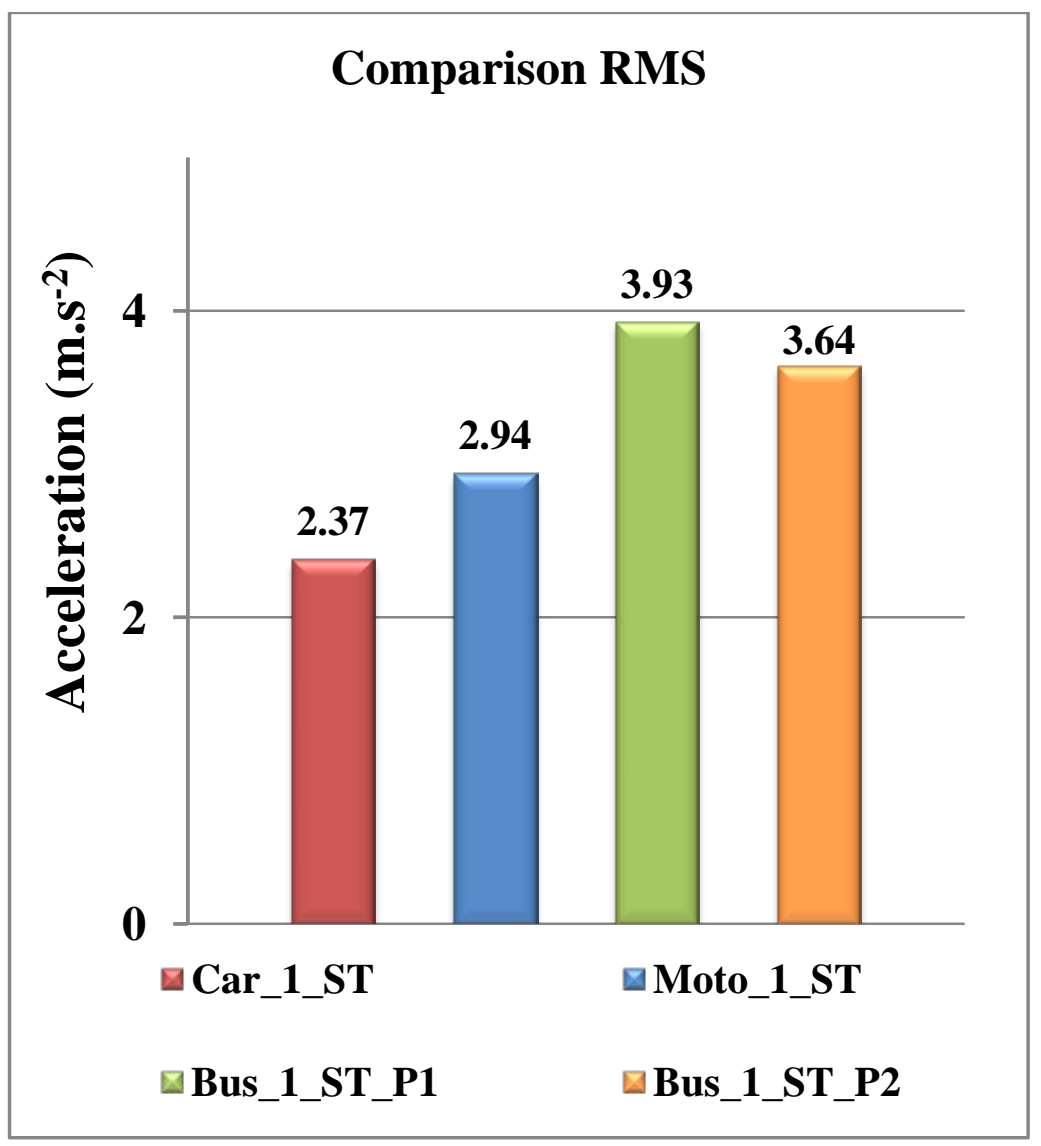

Figure 19. Comparison between RMS of different vehicles

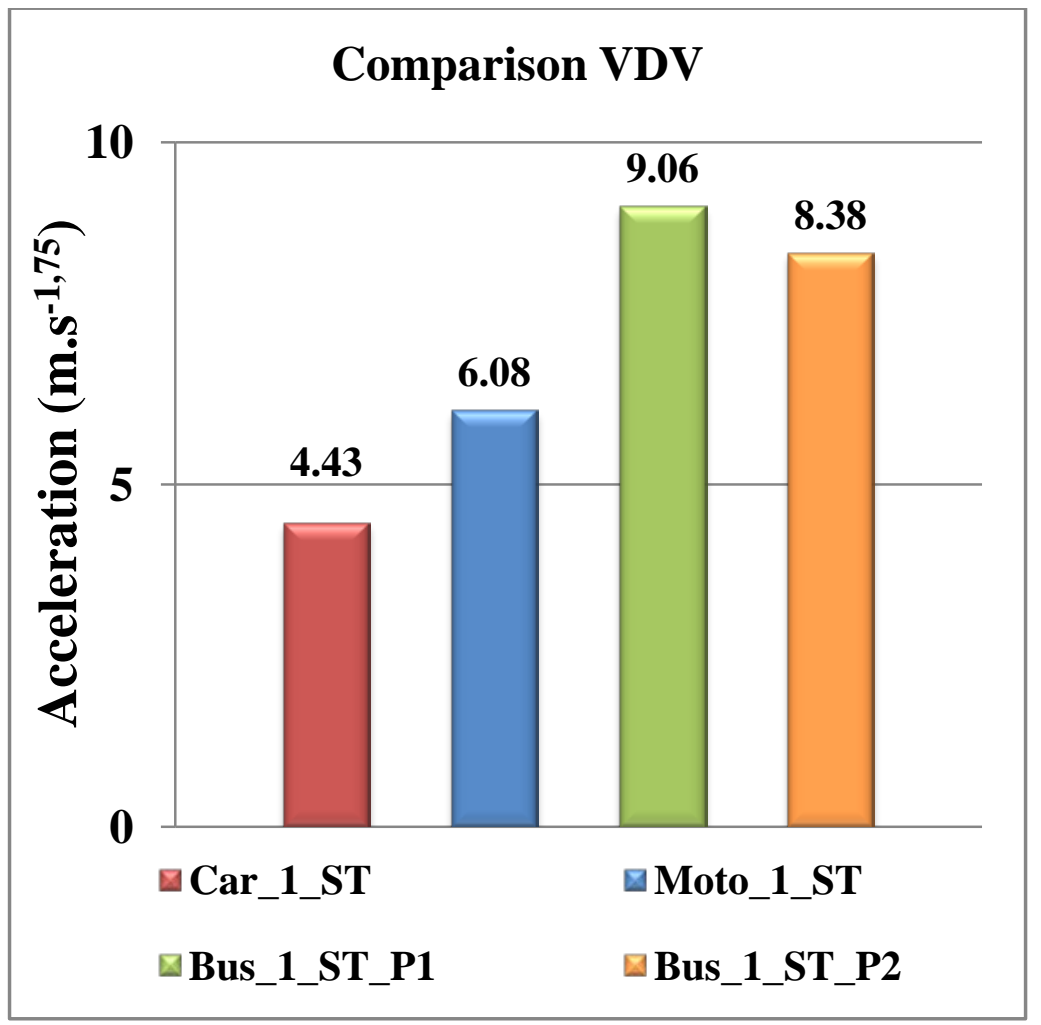

Figure 20. Comparison between VDV of different vehicles 


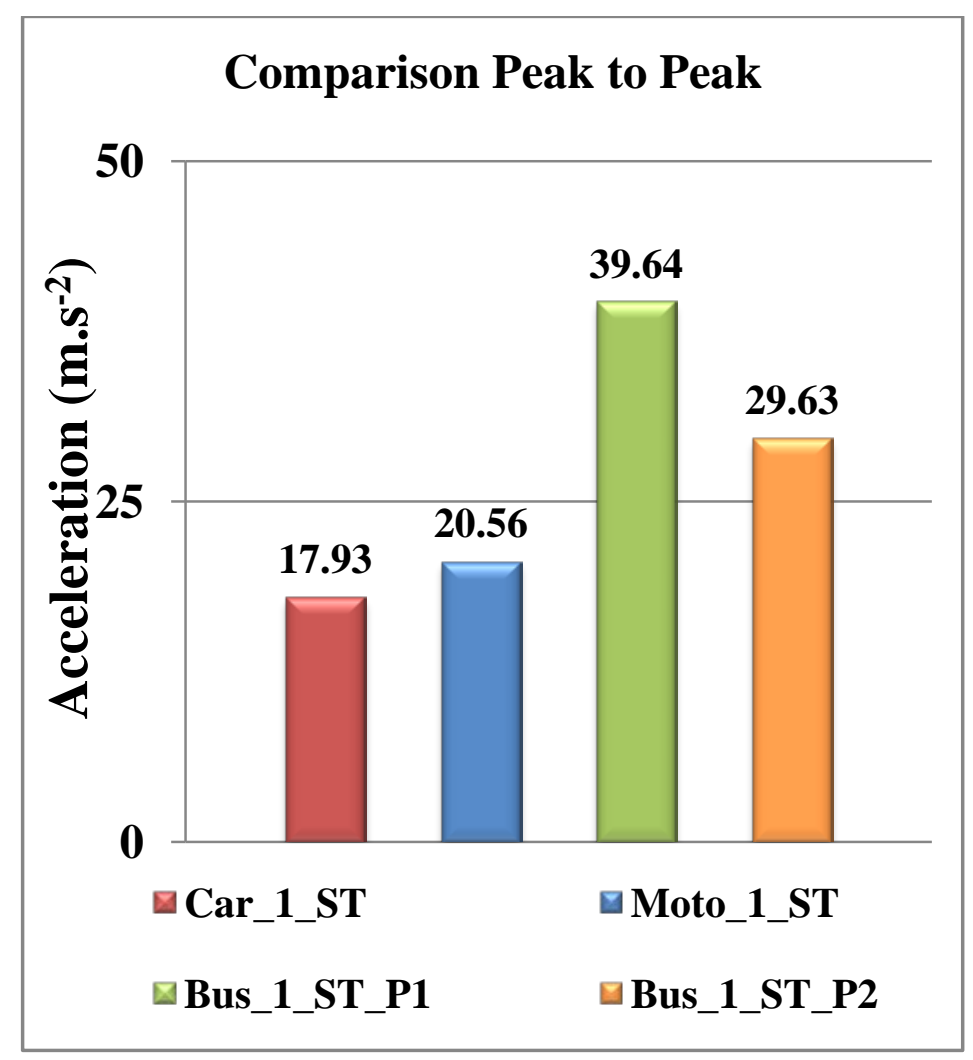

Figure 21. Comparison between Peak to Peak of different vehicles

\section{Conclusions}

This study analyzed several measures of discomfort found in the literature. It evaluated in three type of vehicles: car, motorcycle and bus.

The fact a software based on finite element (not in rigid body dynamics) was used allows in the future for the evaluation of stresses and strains in the components of the models.

The results show that in heavier vehicles such as buses, VDV's values were around $8.5 \mathrm{~m} . \mathrm{s}^{-1,75}$ resulting in average discomfort seconds [8]. In addition, the results obtained by other evaluated measures follow a trend, but this does not always happen. A physical correlation to better understand the effect of abrupt vertical oscillation in human discomfort would be important.

This work did not intend to relate the values obtained with full-scale vehicles, but to make a comparative analysis between different vehicles configurations while passing over a speed bumper. However the correlation of these numerical and experimental results is extremely important for the validation and improvement of numerical models in the near future.

\section{ACKNOWLEDGEMENTS}

The Federal University of São João del Rei, the laboratory Altair, Fapemig, and the whole team that contributed to making this work a reality.

\section{Appendix}

Table 2. Amendments for each vehicle simulation

\begin{tabular}{|c|l|}
\hline Symbol & \multicolumn{1}{|c|}{ Amendments } \\
\hline Car_1_ST ${ }^{(1)}$ & $\begin{array}{l}\text { Car with Between axis } 2453 \mathrm{~mm} \text {, wheel diameter } \\
590 \mathrm{~mm} \text { and speed bump type II. }\end{array}$ \\
\hline Car_2_<WB & Wheelbase with $2250 \mathrm{~mm}$ \\
\hline Car_3_>WB & Wheelbase with $2710 \mathrm{~mm}$ \\
\hline Car_4_<WD & Wheel diameter with $531 \mathrm{~mm}$ \\
\hline Car_5_>WD & Wheel diameter with 656 mm \\
\hline Moto_1_ST & $\begin{array}{l}\text { Motorcycle with between axis } 1446 \text { mm, front } \\
\text { wheel diameter 608 mm, rear wheel diameter 592 } \\
\text { mm and speed bump type II. }\end{array}$ \\
\hline Moto_2_<WB & Wheelbase with $1261 \mathrm{~mm}$ \\
\hline Moto_3_>WB & Wheelbase with $1695 \mathrm{~mm}$ \\
\hline Moto_4_<WD & $\begin{array}{l}\text { Front wheel diameter with } 467 \mathrm{~mm} \text { and rear wheel } \\
\text { diameter with 434 }\end{array}$ \\
\hline Moto_5_>WD & $\begin{array}{l}\text { Front wheel diameter with } 693 \mathrm{~mm} \text { and rear wheel } \\
\text { diameter with 657 }\end{array}$ \\
\hline Bus_2_<WB & $\begin{array}{l}\text { Bus with between axis } 5158 \mathrm{~mm} \text {, wheel diameter } \\
\text { 1011 mm and speed bump type II }\end{array}$ \\
\hline Bus_3_>WB & Wheelbase with 4300 mm \\
\hline Bus_4_<WD & Wheel diameter with $797 \mathrm{~mm}$ \\
\hline
\end{tabular}

(1) This condition remains for each simulation changing only what each tells condition. 


\section{REFERENCES}

[1] ISO 8606 - International Organization for Standardization. Mechanical Vibration Road Surface Profiles - Reporting of Measured Data. International Standard ISO-8608:1995, 30 p, 1995.

[2] Kropac, O. Mucka, P. Effects of longitudinal road waviness on vehicle vibration response. International Journal of Vehicle System Dynamics, Vol. 47, n 2, pp. 135-153, 2009.

[3] Gonzalez, A.; O'Brien, E.J;. Li. Y.Y.; Cashell, K. The use of vehicle acceleration measurements to estimate road roughness. Vehicle System Dynamics, Vol. 46, Issue 6, pp. 485-501, 2008.

[4] ISO 2631 - International Organization for Standardization. Guide for evaluation of human exposure to whole-body vibration. International Standard ISO-2631:1978, 40 p., 1978.

[5] Harris, N.K., Gonzalez, A., OBrien, E.J. McGetrick, P. Characterization of pavement profile heights using accelerometer readings and a combinatorial optimization technique. Journal of Sound and Vibration, Vol. 329, pp. $497-508,2010$.

[6] Mohsen F., Nejat A. L., Hekmat R., Payam J. (2012). Measurement and Analysis of Vibration of Operator in Universal 650, Massey Ferguson 285 \& MF 299 Tractors. International Journal of Mechanics and Applications. DOI: 10.5923/j.mechanics.20120205.06.

[7] Magarido, D. R.. Metodologias para a avaliação dos níveis de vibração em estruturas do ponto de vista do conforto humano (Methods for the evaluation of vibration levels in the human comfort point of view of structure). These at University of Porto, Portugal, 2013.
[8] BS 6841. "Measurement and evaluation of human exposure to whole-body mechanical vibration and repeated shock". London: British Standard Guide, 1987.

[9] Kirstein, J. C. Suspension system optimization to reduce whole body vibration exposure on an articulated dump truck. Dissertação Mestrado em Engenharia Mecânica. Stellenbosch University, Matieland, África do Sul, 2005.

[10] Liang, C. C. e Chiang, C. F. Modeling of a Seated Human Body Exposed to Vertical Vibrations in Various Automotive Postures. Industrial Heath, 2008.

[11] Castro, P. H. Desenvolvimento matemático e implementação numérica de um modelo half-car, incluindo banco, para análise da dinâmica vertical de um veículo. (Development mathematical and numerical implementation of a half-car model, including database for analysis of the vertical dynamics of a vehicle). These at PUC - Minas, Belo Horizonte, 2014.

[12] Freitas, L. M. Estudo da dinâmica vertical de uma suspensão veicular do tipo Macpherson. (A study About the Vertical Dynamics of a MacPherson Vehicle Suspension System). These at University of São Paulo, São Paulo, 2006.

[13] Silveira, M. E., Salco, L. V., Christoforo, A. L. (2012). Numerical simulation of the kinematic behavior of a twist beam suspension via finite element method. International Journal of Mechanics and Applications. DOI: 10.5923/j.jmea.20120206.05.

[14] Bathe, K. J. Finite Element Procedures. Prentice Hall, New Jersey .United States of America. 1996. 768p.

[15] http://www.altair.com/ Altair - Software for Engineering Simulation, Accessed December 2015.

[16] Barbosa, R. S., (2012). Vehicle Vibration Response Subjected to Longwave Measured Pavement Irregularity. International Journal of Mechanics and Applications. DOI: 10.5923/j.jmea.20120202.04. 